\title{
Impact of supportive therapy in reducing anxiety and depression in middle aged cancer patients
}

\author{
Prerna Karulkar ${ }^{1 *}$
}

\section{ABSTRACT}

Cancer patients receiving treatment for their recurrent disease often report the presence of anxiety and depression. In the study, I intended to find out the presence of anxiety and depression in such patients and to identify the effect of supportive therapy in reducing anxiety and depression. Fourteen cancer patients at different stages, undergoing treatment postsurgery, radiotherapy, chemotherapy were selected for therapy sessions. Pre and post therapy evaluation of anxiety and depression were determined by Hospital Anxiety and Depression Scale. The Distress Thermometer was used to measure distress before the therapy sessions. Statistical analysis was done by Wilcoxon signed rank test, using Minitab V.19.2.0 and online test calculator. The results indicated that before the therapy mean scores $( \pm$ standard deviation) of anxieties were $11.92( \pm 1.63)$ and depression $19.78( \pm 1.76)$ which showed the presence of anxiety and depression in cancer patients and after psychotherapy, there was a significant reduction in anxiety $(\mathrm{P}<0.001)$, depression $(\mathrm{P}<0.001)$. Wilcoxon signed Ranked Test was employed and for anxiety Significant difference was found in the medians $(12,8.5)$. The value of $\mathrm{W}$ was 0 which is less than critical value at $\mathrm{N}=14(\mathrm{p}<.05)$ is 21 . Hence, the result was significant at $\mathrm{p}<.05$. For depression, Significant difference was found in the medians $(10,7.5)$. The value of $\mathrm{W}$ was 0 which is less than critical value at $\mathrm{N}=14(\mathrm{p}<.05)$ is 21 . Hence, the result was significant at $p<.05$. Supportive therapy helps to reduce the levels of anxiety and depression. Therefore, psychotherapeutic interventions should be encouraged along with chemotherapy, radiotherapy to promote positive mental health and to obtain full benefit of pharmacological treatment.

\section{Keywords: Mental Health, Depression, Anxiety, Psychological Distress, Supportive Therapy}

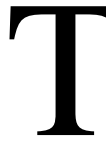

This century has recognized cancer as the major health problem due to the hyperbolic prevalence of cancer in recent years and its impact on varied aspects of physical, psychological and social life (Sadoughi, 2017).

Cancer is caused by an uncontrolled cell growth and tumour formation, and by attacking healthy tissues of the body causes severe health problem and, as a result, death. It is one in all the foremost common non-infectious diseases (Winters-Stone et al., 2012).

\footnotetext{
${ }^{1}$ School of Social Sciences, Devi Ahilya Vishwavidyalaya, Indore, Madhya Pradesh, India *Responding Author
} 
The diagnosis of cancer almost inevitably features a devastating consequence on patients and their families. Although some families deal with the crisis that ensues without seeking professional help, others may find that they do not have the emotional resources to address the implications for their social role and feel overburdened, helpless, angry, and despondent. Depression and anxiety are common among individuals diagnosed with cancer. They are frequently triggered by stress and cancer is one of the most stressful events that an individual may experience. Cancer treatment is also hampered due to the presence of those factors. Self-esteem and confidence are also severely affected by the changes in body image. Family and work roles may be altered. Individuals may feel grief at these losses and changes. Physical symptoms like pain, nausea or extreme tiredness conjointly appear to cause emotional distress. People may additionally fear death, suffering, pain and fear of all the unknown things that lie ahead. As an example, the patients with untreated depression or anxiety may be less likely to take his cancer treatment medication and continue good health behaviours because of fatigue or lack of motivation. They may also withdraw from family or other social support systems, which suggest they are not going to elicit the needed emotional and financial support to deal with cancer. This successively may end in increasing stress and feelings of despair (American Society of Clinical Oncology (ASCO) Depression and Anxiety. 2012. Retrieved from: URL: http://www.cancer.net). Mostly anxiety causes cancer patients to worry about the future and illness a lot and in turn neglect their own health.

\section{Anxiety}

Anxiety is defined as the fearful anticipation of future danger or misfortune accompanied with feelings of dysphoria or somatic symptoms of tension (American Psychiatric Association, 2013).

Anxiety can be either state anxiety (short term) or trait anxiety (long term). Trait anxiety reflects a stable tendency across the lifespan, a habitual tendency to be anxious in general. State anxiety is in the anticipation of threatening situations (whether they are actually deemed threatening or not), the anxiety felt at the present. Cancer patients face state anxiety, it is due to the present changed conditions.

Anxiety in cancer patients is a normal response to perceived threat slowing of body functions, change in appearance, social roles, family disturbance, death etc.

Anxiety produces a variety of typical symptoms and signs.

Symptoms of autonomic over-activity: palpitation, sweating, restlessness, reassuranceseeking.

Changes in thinking: apprehension, worry and poor concentration.

Physical symptoms: muscle tension, fatigue.

Pathological anxiety is identified by:

1. Being out of proportion to the amount of threat.

2. Persistence or worsening without intervention.

3. Level of symptoms which is undesirable regardless of the level of threat (these include periodic panic attacks, severe physical symptoms, and abnormal beliefs such as thoughts of unexpected death).

4. A disturbance of usual or necessary functioning.

Along with anxiety, cancer patients often exhibit depressive symptoms. 


\section{Depression}

Depression otherwise called as clinical depression or depressive disorder is a common and grave mood disorder. People who suffer from depression experience obstinate feelings of unhappiness and bleakness and lose interest in activities they once enjoyed. Individuals can also present physical symptoms like long-lasting pain or digestive issues and even emotional problems due to depression. These symptoms must be present for a minimum of a fortnight to be diagnosed with depression.

These symptoms must cause the individual clinically substantial distress or impairment in societal, professional or other important areas of functioning, to receive a diagnosis of depression. The symptoms must also not be due to other medical condition or substance abuse.

Depression in Cancer Patients: It is normal to be sad over the changes that cancer brings to an individual's life. The future now becomes indeterminate, which may have seemed so sure before. Some dreams and plans may be lost forever. But if a person remains sad for a long time or has trouble completing day-to-day activities, that person may have clinical depression. In reality, up to 1 in 4 people with cancer have clinical depression. Clinical depression causes great distress, impairs functioning and might even make the person with cancer less ready to follow their cancer treatment plan.

\section{Symptoms of clinical depression in cancer patients}

- Ongoing unhappy, hopeless, or "empty" mood for all of the day

- Loss of interest or pleasure in almost majority of activities most of the time

- Major weight loss (when not dieting) or weight gain

- Being slackened down or restless and agitated on daily basis, enough for others to notice

- Extreme weariness (fatigue) or loss of energy

- Trouble sleeping with early waking, sleeping excessively or not being able to sleep in the least

- Trouble concentrating, thinking, remembering or making decisions

- Feeling guilty, worthless and helpless

- Recurrent thoughts of death or suicide (not just fear of death), suicide plans or attempts

Some of these symptoms like weight changes, fatigue, or even forgetfulness is also caused by the cancer itself and its treatment. But if five or more of these symptoms happen on a daily basis for two weeks or more, or are severe enough to interfere with normal activities, it would be depression (Staying Healthy: How to Stay Healthy. (n.d.). Retrieved 10, 2020, from https://staging.cancer.org/healthy.html). With the feelings of anxiety and depression, cancer patients many a times experience psychological distress.

\section{Distress}

Distress could be a general term used to describe hostile feelings or emotions that impact the level of working. In other words, it is psychological discomfort that restricts the activities of daily life. Psychological distress may result in undesirable views of the environment, others and also the self. Sadness, anxiety, distraction and symptoms of psychopathy are manifestations of psychological distress. Traumatic experiences like the death of a loved one also causes psychological distress. Psychological distress can be defined as a dysfunctional 
response to any stressful situation. Psychological distress occurs when external events or stressors place demands that people are unable to deal with. Foremost life transitions can be a source of psychological distress as some people find difficulty in adjusting to new situation. Sudden unexpected events like an accident of a loved one or being fired from a job, can also cause psychological distress.

Cancer and other medical illness can also be a source of distress in people. It is recommended internationally to do routine screening for distress as a necessary standard for good cancer care (Grassi et al., 2013).

\section{Supportive Psychotherapy}

Supportive psychotherapy is the integration of various psychotherapeutic approaches to provide therapeutic support. It includes components from therapeutic schools such as psychodynamic, cognitive-behavioural, and interpersonal conceptual models and techniques (Winston, 2004). Supportive psychotherapy aims at reducing or in relieving the intensity of demonstrated or showed symptoms, distress or disability. It also reduces the extent of behavioural disruptions caused by the patient's psychic conflicts or disturbances (Dewald, 1994). The techniques used in supportive therapy are praise, advice, reassurance, reframing, guidance, clarification, confrontation and interpretation. The defences are confronted if they are grossly maladaptive (primitive projection or splitting) or threaten the frame of treatment. The stance of therapist in supportive psychotherapy emphasizes the real relationship, based on the interest and receptiveness and reflected in the therapeutic alliance. With the use of accurate empathic responses and validation of feeling states, the therapeutic alliance is actively supported. The collaborative effort of patient and therapist brings about the change elicited. It mainly focusses on increasing self-esteem and not self-understanding to accomplish patient goals and therapist objectives (Rosenthal et al., 1999). Some commonly used strategies of supportive therapy are : to manage the transference, to hold and contain the patient, to lend psychic structure to the therapy, to maximize the adaptive coping mechanism, to provide a role model for identification, to focus on the present, to encourage patient activity, to educate the patient and the family and to manipulate the environment(Misch, 2000).

In this study, anxiety is taken as the perceived fear of unknown due to cancer in cancer patients. Depression is showing disinterest in routine activities and loss of motivation to go on with life due to long term illness. Distress is inability of people suffering from cancer to cope with the changed situation of their life. Supportive Therapy in this study is providing support to the cancer patients after making therapeutic alliance by various techniques to reduce their anxiety, depression and distress. The purpose of this study is to evaluate the impact of Supportive therapy in reducing anxiety and depression in cancer patients at all the stages of cancer treatment, with the help of following objectives and hypothesis.

\section{Objectives}

1. To study the impact of Supportive therapy in reducing anxiety in cancer patients.

2. To study the impact of Supportive therapy in reducing depression in cancer patients.

\section{Hypothesis}

1. There is no significant change in the anxiety levels of the patients before and after Supportive Therapy.

2. There is no significant change in the depression levels of the patients before and after Supportive Therapy. 


\section{REVIEW OF LITERATURE}

The purpose of this study is to evaluate the impact of Supportive therapy in reducing anxiety and depression in middle aged cancer patients. Various researches have been done in the past to show the presence of anxiety and depression in cancer patients, to study the effectiveness of Psychotherapies including Supportive therapy in reduction of anxiety and depression in such cases. A detailed review of literature is given below-

In the present study, sample is derived from oral cancer and breast cancer patients. Oral (Head and Neck) cancers include cancers in the larynx, throat, lips, mouth, nose, and salivary glands. Tobacco and heavy alcohol use, infection with human papillomavirus (HPV) increase the risk of head and neck cancers. Breast cancer forms in the cells of the breasts. Breast cancer is the most commonly diagnosed cancer after skin cancer. Breast cancer can occur in both men and women, but it is more common in women (National Cancer Institute). A study done on breast cancer patients has revealed that patients with breast cancer show symptoms of anxiety and depression on diagnosis of the illness, during the course of treatment and sharp level of increase on recurrence of the disease (Burgess et al., 2005).

Cancer is a distressing and debilitating disease. Cancer care professionals should be able to discriminate morbid anxiety from normal anxiety and should be able to deal with it (Stark, 2000). During the process of treatment, a patient may suffer from distress, depression and anxiety. Many factors can contribute in the development of anxiety in cancer patient (Pitman et al., 2018). It can be due to economic condition, lack of support from family and society and unemployment (Wen,2019). The education of the patient also has an implication in the presence of depression and anxiety (Khalil et al., 2016). The distress also depends on the stage of cancer and treatment procedures. The individual characteristics like age, gender, religion, marital status and other physical, psychological disability or psychiatric condition also play an important role in causing anxiety and depression in cancer patients.

A study done on Oral cancer patients demonstrated that during the first six months of diagnosis, patients feel depressed due to loss of speech, loss of sense, loss of libido, dry mouth, swallowing, high dosage of pain killers, trouble with social contact, social eating, weight loss, nutritional supplements( $\mathrm{Wu}$ et al., 2016).Factors that may contribute to depression and anxiety among people with cancer are:- 


\begin{tabular}{|c|c|}
\hline $\begin{array}{l}\quad \text { Individual characteristics } \\
\text { - Age } \\
\text { - Gender } \\
\text { - Ethnicity } \\
\text { - Sexuality } \\
\text { - Disability } \\
\text { - Religion } \\
\text { - Biological factors (e.g. genetics) } \\
\text { - Co-morbid health conditions } \\
\text { - Marital \& cohabitation status }\end{array}$ & $\begin{array}{l}\text { Psychological response to diagnosis } \\
\text { - Psychological distress } \\
\text { - Coping behaviour } \\
\text { - Hopelessness } \\
\text { - Denial } \\
\text { - Anger } \\
\text { - Fear } \\
\text { - Grief } \\
\text { - Resilience } \\
\text { - Concern for others } \\
\text { - Change in self image }\end{array}$ \\
\hline $\begin{array}{l}\text { Social \& contextual factors } \\
\text { - Education level } \\
\text { - Employment status \& characteristics } \\
\text { - Household income \& wealth } \\
\text { - Family } \\
\text { - Social support } \\
\text { - Stressful life events (e.g. bereavement) } \\
\text { - Healthcare system } \\
\text { - Welfare system }\end{array}$ & $\begin{array}{l}\quad \text { Characteristics of cancer } \\
\text { - Diagnosis experience } \\
\text { - Symptoms } \\
\text { - Type of cancer } \\
\text { - Stage } \\
\text { - Grade } \\
\text { - Prognosis \& curability } \\
\text { - Functional decline } \\
\text { - Recurrence }\end{array}$ \\
\hline $\begin{array}{l}\quad \text { Prior psychological factors } \\
\text { - Pre-existing psychiatric disorder(s) } \\
\text { - Previous suicidal behaviour } \\
\text { - Personality (e.g. neuroticism) } \\
\text { - Prior coping behaviour (e.g. adverse } \\
\text { health behaviours) }\end{array}$ & $\begin{array}{l}\quad \text { Cancer treatment } \\
\text { - Treatment modality \& dose (e.g. } \\
\text { radiotherapy, chemotherapy) } \\
\text { - Side effects } \\
\text { - Long-term complications (e.g. infertility, } \\
\text { secondary cancers) } \\
\text { - Setting (e.g. inpatient, outpatient) } \\
\text { - Treatment burden \& length } \\
\text { - Cost of treatment } \\
\text { - Response to treatment } \\
\text { - Phase (e.g. acute, palliative) }\end{array}$ \\
\hline
\end{tabular}

NOTE: Reprinted from Niedzwiedz, C.L., Knifton, L., Robb, K.A. et al. Depression and anxiety among people living with and beyond cancer: a growing clinical research priority. BMC Cancer 19, 943 (2019). https://doi.org/10.1186/s12885-019-6181-4

Patients often do not get psychological support or treatment due to several factors like lack of awareness, social apathy and an absence of support available or offered and unwillingness to share own feelings due to stigma attached to it (Niedzwiedz et al., 2019).

Cancer treatment of patients is generally carried over extended periods of time. The various treatment procedures like surgery, radiotherapy, chemotherapy is painful, very energy consuming and patients often lose their perseverance and will to continue to fight the illness. Moreover, the treatment also leads to a change in physical appearance like hair loss, darkening of skin, massive weight loss and many more problems which decrease self-esteem and consequently self-confidence. This intense experience leaves them overwhelmed and drained. To be able to sustain the treatment, they must get support from the family and the doctor.

Age also plays an important role in increasing the prospect of cancer metastasis, lengthen the duration of disease, inability to withstand harsh treatment procedures. These conditions make the older patients more prone to anxiety and depression (Nikbakhsh, 2014). 
Various other factors are also accounted for anxiety in cancer patients like personality traits and coping styles of individuals. In a study, neurotic personality trait, a coping style of helplessness/hopelessness, and female sex were positively correlated with significant anxiety, while a coping style of fatalism was negatively correlated (Shimizu et al., 2015).

Several studies have indicated that depression at these stages can lead to serious and farreaching negative consequences in patients with cancer reducing their quality of life and causing severe suffering, a desire for early death and suicide, as well as psychological distress in family members (Hodges, 2005).

Psychotherapeutic interventions can help them to a considerable extent during this phase. Along with the physical symptoms, psychological defence mechanism like denial is also observed frequently in such patients. It can be taken care of by psychotherapeutic intervention devised according to the patient's needs (Cohen, 2004).

The various therapies helpful in managing anxiety and depression in cancer patients are Cognitive Behavioural Therapy, Supportive Therapy, Problem solving Therapy, Group Psychotherapy and some novel approaches like Life Review Interview and Dignity Therapy (Akechi, 2012). With supportive therapy skills, a therapist must be well versed in medical issues and milieus and should have a deep understanding of the patient's physical traumas (Lederberg, 2011).

Support provided through group therapies are also very valuable in terminally ill cancer patients as they dealt with issues related to existence and death (Spiegel, 1978; Yalom, 1977).

Supportive psychotherapy is defined by Pinsker et al. as "a dyadic treatment characterized by use of direct measures to ameliorate symptoms and to maintain, restore, or improve selfesteem, adaptive skills, and ego function" (Pinsker et al., 1991).

Supportive therapy is a sensitive psychotherapeutic intervention for relieving stress and anxiety in cancer patients. Supportive therapy has proved to be very effective on breast and ovarian cancer patients. They showed improved quality of life and reduction in anxiety and depression post psychotherapeutic interventions (Mukherjee, 2017). Supportive psychotherapy concentrates around the patient and is very flexible approach that can be modified with different patients. This approach does not follow any fixed guidelines or rules. Generally, Supportive therapy begins with building relationship of trust with the patient so that the patient can share his feelings freely. It mainly puts emphasis on addressing the patient's concerns, attending, understanding, accepting, listening and empathizing with the patient's distress. (Linn, 1982; Stedeford, 1979).

All these studies were conducted either on particular type of cancer patients or during particular stage of cancer treatment, but in this study oral and breast cancer patient at various stages of cancer from recently diagnosed, undergoing chemotherapy, radiotherapy, postsurgery, all were taken into account for their levels of anxiety and depression.

\section{METHODOLOGY}

\section{Sample}

For the study 14 cancer patients at different stages of cancer treatment were chosen with purposive sampling at Indian Institute of Head and Neck Oncology, Indore. Six of these

(c) The International Journal of Indian Psychology, ISSN 2348-5396 (e)| ISSN: 2349-3429 (p) | 305 
patients were suffering from breast cancer and eight were oral cancer patients; 8 were female patients and 6 were males. All patients were in the 35 years to 55 years age group. They all belonged to the low and middle income group. The study took place between January to April 2020.

\section{Research Design}

The research aimed to study the impact of Supportive Therapy in reducing anxiety and depression in cancer patients. Thus, the study employed intervention based experimental design. Here the independent variable is Supportive Therapy and dependent variables are anxiety and depression.

\section{Psychological tools}

NCCN distress thermometer: In this study NCCN distress thermometer was used for initial screening of distress (Grassi et al., 2013). The scale measures distress on the scale of 0 to 10 . A person is considered to be distressed if the score is more than 3 . The scale is divided in various parts and questions are asked about feelings in past week based on physical problems (appearance, breathing, fatigue, pain etc), family problems (children, spouse etc), practical problems (housing, transport, work, finance etc.), emotional problems (sadness, fear, worry, loss of interest etc), spiritual and other problems.

Hospital Anxiety and Depression Scale (HADS): It was used for finding the levels of anxiety and depression. It was found to be a useful instrument for screening depression and anxiety in clinical settings. It provided clinicians with an acceptable, reliable, valid and easy to use practical tool for identifying and quantifying depression and anxiety (Zigmond, 1983; Michopoulos et al., 2008). Hospital Anxiety and Depression Scale has been used on cancer in-patients and it proved to be simple, specific and effective in various studies (Razavi et al., 1990). HADS has two subscales for anxiety (seven items) and for depression (seven items). For each item, the participant respondents were asked to indicate which of the 4 options (rated from 3 to 0; score range, 0-42) comes closest to describing how they have been feeling in the past week. The score of 0-7 means without clinical symptoms of anxiety or depression, 8-10 mild anxiety or depression and 11-21 symptomatic anxiety or depression. The spectrum of depression means cumulation of symptomatic plus mild depression and the spectrum of anxiety means cumulation of symptomatic plus mild anxiety.

\section{Procedure}

The patients were approached and were informed about the study. They were explained the questions in Hindi before and during the administration of the test.

According to the need and severity, the treatment plan was devised for each patient. The treatment comprised of four sessions of 35 to 40 minutes each of Supportive therapy after interval of one week.

In the first session, rapport was built by asking their routine, likes, dislikes, family, support and patients were psycho educated about illness, therapy; few relaxing techniques were introduced.

In the second session, scheduling their routine, some more coping strategies like sharing their feelings with family members, writing journal, keeping busy with work and leisure activities like reading, walking, art, music were presented. Meditation and relaxation techniques were demonstrated. 
In the third session, their routine was discussed and their challenges in following it were addressed. Importance of meditation and spirituality was reinforced and positive thinking was emphasized. Motivation was provided for engaging in physical activity according to the capability of an individual.

During the fourth session, again relaxation techniques like slow rhythmic, deep breathing, muscle tensing, gentle yoga, spiritual support and meditation were emphasized for relapse prevention. They were encouraged to be busy and active as far as possible for them. The family members were also provided emotional support during the whole process.

Supportive therapy sessions included techniques like praise, reassurance, normalizing, encouragement, reframing, advice, guidance, persuasion and teaching. It targeted (i) Selfesteem by expressing acceptance, approval, interest, respect and admiration (ii) Change in specific behaviours(iii) Daily life functioning(iv) Relationships.

After the completion of the fourth session, post therapy session evaluations were done.

\section{Statistical Analysis}

The statistical techniques used were -

Descriptive statistics- Mean, Median, Standard Deviation.

Inferential statistics- Wilcoxon signed rank test

Standard scoring procedures were followed. The mean and standard deviation (SD) were calculated to determine the central tendency and the variability of the scores. To test the significance of difference between pre and post-psychotherapy sessions, non-parametric statistic Wilcoxon signed rank test was done. Statistical analysis was done using Minitab 19.2.0 software. $P<0.05$ was considered as statistically significant.

\section{RESULTS}

Table 1 Anxiety and Depression, pre and Post-test score with mean and SD

\begin{tabular}{|l|l|l|l|}
\hline & Mean & SD & N \\
\hline Anxiety & & & \multirow{2}{*|}{} \\
Pre-test & 11.92 & 1.63 & 14 \\
Post-test & 8.64 & 1.55 & \\
\hline Depression & & & 14 \\
Pre-test & 9.78 & 1.76 & \\
Post-test & 7.42 & 1.69 & \\
\hline
\end{tabular}

On pre psychotherapy evaluation, it was seen that for anxiety pre-test score mean $=11.92$ with $\mathrm{SD}=1.63$ and post therapy anxiety score was mean $=8.64$ with $\mathrm{SD}=1.55$ as shown in [Table 1]

It was evident from [Table 1], pre therapy score for Depression, mean $=9.78$ with $\mathrm{SD}=1.76$ and post therapy score was mean $=7.42$ with $\mathrm{SD}=1.69$. It was apparent that there was significant difference in the pre and post evaluations.

Supportive psychotherapy proved to be very beneficial and helped in reducing anxiety and depression in cancer patients. 
Table 2 Wilcoxon Signed Rank CI: Pre-test Anxiety, Post-test Anxiety

\begin{tabular}{|c|c|c|c|c|}
\hline \multicolumn{5}{|c|}{$\begin{array}{l}\text { Wilcoxon Signed Rank CI: Pre-test Anx } \\
\text { Method }\end{array}$} \\
\hline $\begin{array}{l}\text { Method } \\
\eta: \text { median of } \\
\text { Anx }\end{array}$ & Pre & test Anx & Post-test & \\
\hline \multicolumn{5}{|c|}{ Descriptive Statistics } \\
\hline Sample & $\mathbf{N}$ & Median & CI for & $\begin{array}{l}\text { Achieved } \\
\text { Confidence }\end{array}$ \\
\hline Pre-test Anx & 14 & 12.0 & $(11,13)$ & $94.84 \%$ \\
\hline Post-test Anx & 14 & 8.5 & $(8,9.5)$ & $94.84 \%$ \\
\hline
\end{tabular}

\section{Result Details}

$W$-value: 0

Mean Difference: 2.93

Sum of pos. ranks: 105

Sum of neg. ranks: 0

Z-value: -3.2958

Mean $(W): 52.5$

Standard Deviation $(W): 15.93$

Sample Size $(N): 14$

Significance Level: 0.5

Hypothesis : Two tailed

Result 1 - Z-value

The value of $z$ is-3.2958. The $p$-value is .00096 .

The result is significant at $p<.05$.

Result 2 - $W$-value

The value of $W$ is 0 . The critical value for $W$ at $N=14(p<.05)$ is 21 .

The result is significant at $p<.05$.

Our first hypothesis states that there was no significant difference in pre-test and post-test evaluations of levels of anxiety, but it can be seen from Table 2 , the value of $\mathrm{W}=0$ and critical value at $\mathrm{N}=14$ is 21 at $\mathrm{p}<.05$. Hence the result was significant at $\mathrm{p}<.05$ and thus we rejected the first hypothesis. There was significant difference in the medians -Pre-test $=12$ and Post-test $=8.5$. 
Figure 1 Change In Anxiety Levels

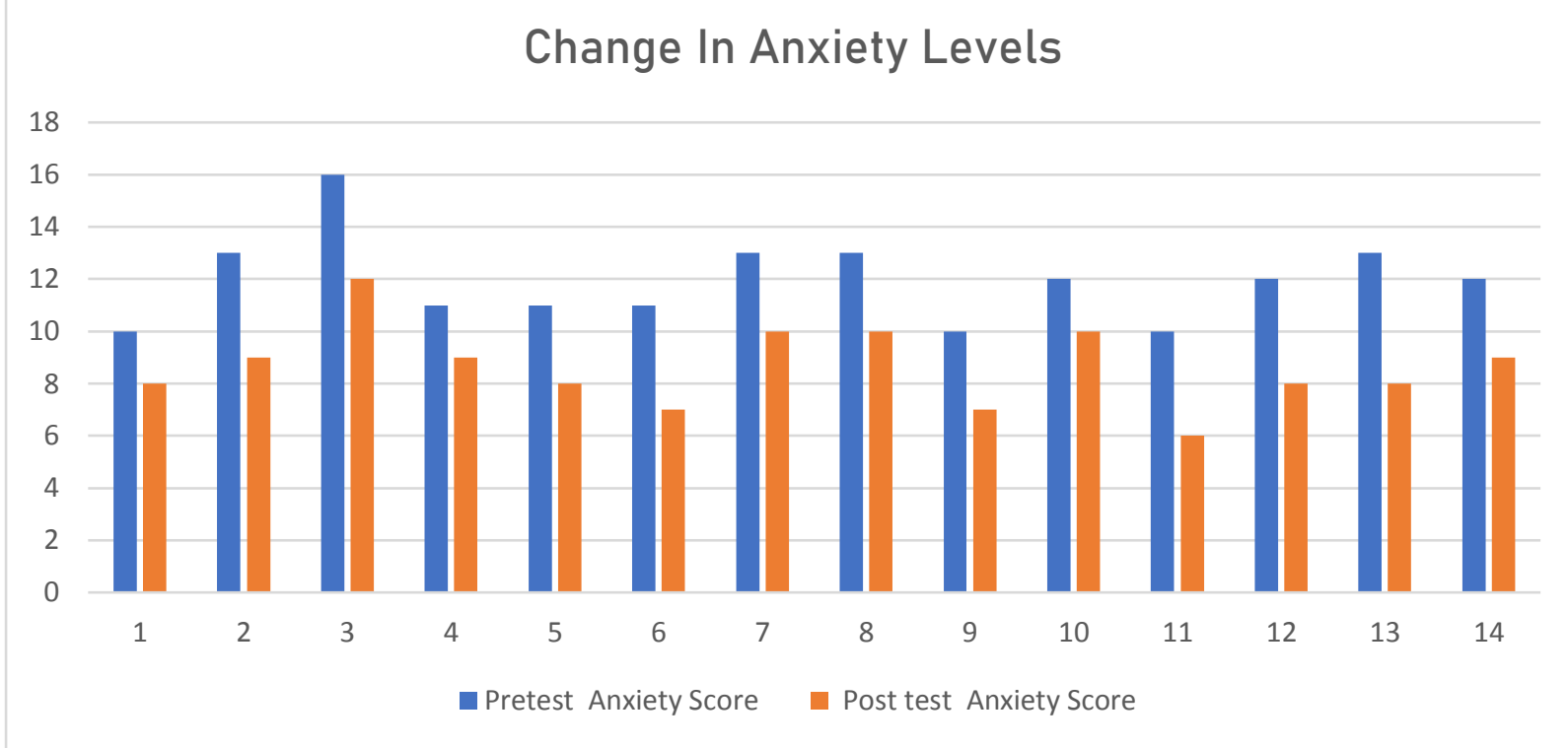

Table 3 Wilcoxon Signed Rank CI: Pre-test Dep, Post-test Dep

Wilcoxon Signed Rank CI: Pre-test Dep, Post-test Dep

Method

$\eta$ : median of Pre-test Dep, Post-test Dep

Descriptive Statistics

\begin{tabular}{|c|c|c|c|c|}
\hline Sample & $\mathbf{N}$ & Median & $\begin{array}{l}\text { CI for } \\
\eta\end{array}$ & $\begin{array}{l}\text { Achieved } \\
\text { Confidence }\end{array}$ \\
\hline $\begin{array}{l}\text { Pretest } \\
\text { Dep }\end{array}$ & 14 & 10.0 & $\begin{array}{l}(8.5, \\
11)\end{array}$ & $94.84 \%$ \\
\hline $\begin{array}{l}\text { Posttest } \\
\text { Dep }\end{array}$ & 14 & 7.5 & $\begin{array}{l}(6.5, \\
8.5)\end{array}$ & $94.84 \%$ \\
\hline
\end{tabular}

$W$-value: 0

Mean Difference: 3.79

Sum of pos. ranks: 105

Sum of neg. ranks: 0

$Z$-value: -3.2958

Mean $(W): 52.5$

Standard Deviation $(W): 15.93$

Sample Size $(N): 14$

Significance Level: 0.5

Hypothesis : Two tailed

Result 1 - Z-value

The value of $z$ is-3.2958. The $p$-value is .00096 .

The result is significant at $p<.05$.

Result 2 - W-value

The value of $W$ is 0 . The critical value for $W$ at $N=14(p<.05)$ is 21 .

The result is significant at $p<.05$.

(c) The International Journal of Indian Psychology, ISSN 2348-5396 (e)| ISSN: 2349-3429 (p) | 309 
Our second hypothesis states that there was no significant difference in pre-test and post-test evaluations of levels of depression, but it can be seen from Table 3 ,the value of $\mathrm{W}=0$ and critical value at $\mathrm{N}=14$ is 21 at $\mathrm{p}<.05$. Hence the result was significant at $\mathrm{p}<.05$ and thus we rejected the second hypothesis. There is significant difference in the medians- Pre-test $=10$ and Post-test $=7.5$.

Figure 2 Change in Depression Levels

\section{Change in Depression Levels}

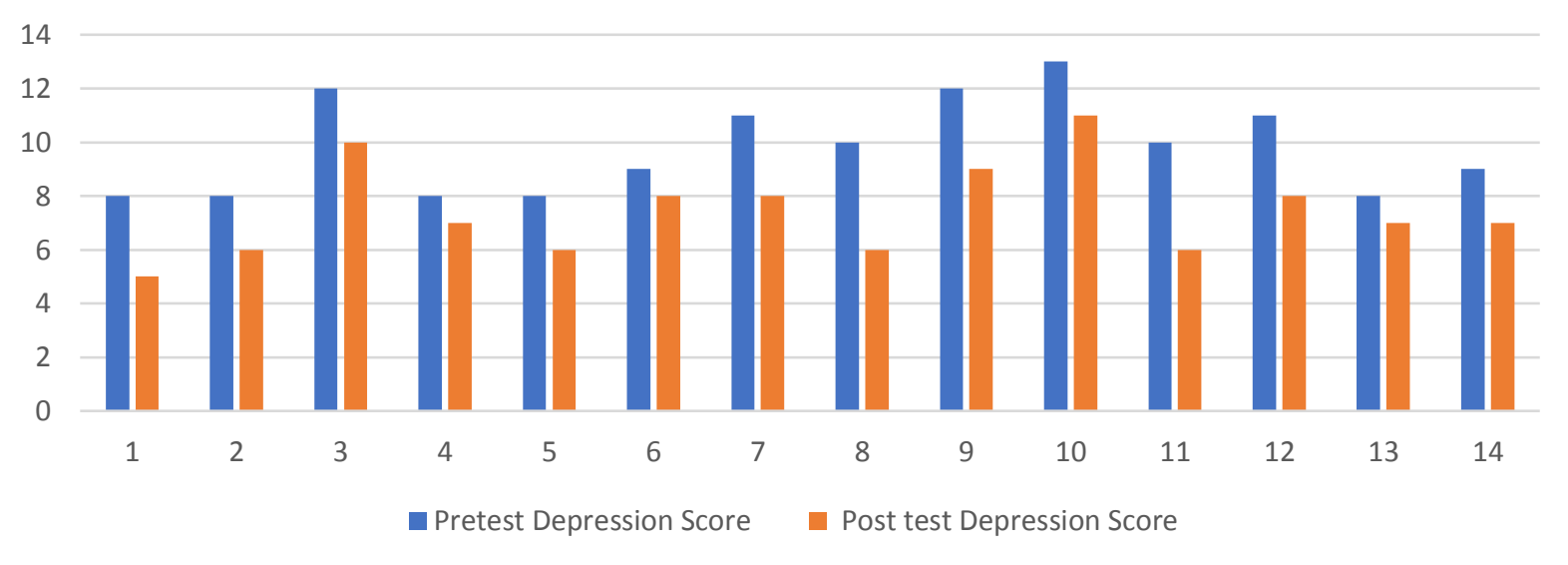

\section{DISCUSSION}

Apart from the physical distress, the cancer patients face a lot of psychological distress and anxiety which increases their pain and trauma during the course of their treatment. The psychological impact cannot be ignored and should be taken care of effectively for better recovery (Arving, 2013). Cancer treatment disrupts the emotional, social life of an individual. Sometimes, social relations might add to the distress instead of buffering against cancer (Pardue, 1989).

The impact of surgery can be very devastating as it sometimes need amputation resulting in disfigurement. The side effects of radiotherapy include skin darkening, appetite loss and during chemotherapy, one might face nausea, vomiting, fatigue and hair loss. The fear of recurrence of cancer is always present and has adverse effect on physical and psychological health of the patient (Endicott, 1984).

The long duration of the treatment, long stay at hospital and increased time in rehabilitation causes depression and distress in patients (Cordova, 2017).

Apart from physical pain, the patients suffer a lot due to dependency on others, worries about future, financial problems. Marital relations of patients also suffer due to lack of interest in sexual relations. Women, in particular have fear of disrupted body image and lose of position in family and society (Ming, 2002). Family members of the cancer patients also go through a lot of agony during this phase. The emotional needs of each other should be addressed by them, especially children and the elderly. A patient needs kind, compassionate and empathetic people around at this time.

In the present study, it was seen in Table 1 that in pre-therapeutic evaluation, high levels of anxiety and depression were present in the patients during different stages of cancer treatment. 
Due to the fear of side effects of radiation and chemotherapy, many patients do not want to continue the treatment. At each step, encouragement and motivation is needed to complete the treatment.

As is evident from Table 2 and Table 3, Supportive therapy helps to reduce anxiety and depression in cancer patients. Supportive therapy helps in reducing anxiety and depression and subsequently in coping with the present situation rationally and improving quality of life. Many studies have shown these results ((Mukherjee, 2017; Linn, 1982; Stedeford, 1979; Wu, 2003). Supportive therapy provides sense of well-being and make patients lead stress free lives and recuperate better from cancer (Akechi, 2012). It works on improvement in emotional, psychological, social aspects and provides support and mental strength to continue the long battle with positive mind frame and improve quality of life.

The study has some limitations and implications. The present study was conducted on small sample and for a short duration. Such studies need large samples and longitudinal method for at least a few months. Other factors like economic status, marital status was not considered. For future studies, the study can be replicated on large sample for longer duration keeping all the other variables in consideration. However, from this study it was evident that gender is not related to the psychological impact. Anxiety and depression affect both equally. This study aims to create a greater awareness of the psychological dimension in treatment of cancer patients.

In further research, use of pharmacological intervention such as use of SSRIs along with psychotherapy should also be considered.

\section{CONCLUSION}

It is apparent in the study, patients undergoing treatment for cancer are highly distressed and face severe anxiety on diagnosis, during treatment with procedures like Chemotherapy, Radiotherapy and post-surgery. To alleviate distress and reduce anxiety, psychotherapeutic interventions can be applied to reduce their suffering and alleviate pain.

Typically, cancer treatment in India emphasize physical treatment and ignore psychological supportive care, which is an important part of cancer care. More specifically, cancer hospitals should radically change their treatment approach and employ psychological tools and therapies in conjunction with physical treatment of cancer.

\section{REFERENCES}

Akechi, T. (2012). Psychotherapy for depression among patients with advanced cancer. Japanese journal of clinical oncology, 42(12), 1113-1119.

American cancer society https://www.cancer.org/healthy.html

American Society of Clinical Oncology (ASCO) Depression and Anxiety. 2012. available at: URL: http://www.cancer.net.

Arving, C., Thormodsen, I., \& Brekke, G. (2013). Early rehabilitation of cancer patients-a randomized controlled intervention study, bmc cancer, Vol. 13 (9). Dimensions in oncology nursing: journal of the Division of Nursing, 3(1).

Burgess, C., Cornelius, V., Love, S., Graham, J., Richards, M., \& Ramirez, A. (2005). Depression and anxiety in women with early breast cancer: five year observational cohort study. Bmj, 330(7493), 702.

Cohen ST. (2004) Block S. Issues in psychotherapy with terminally ill patients, Palliat Support Care, vol. 2 (pg. 181-9) 
Cordova, M. J., Riba, M. B., \& Spiegel, D. (2017). Post-traumatic stress disorder and cancer. The Lancet Psychiatry, 4(4), 330-338.

Dewald, P. A. (1994). Principles of supportive psychotherapy. American journal of psychotherapy, 48(4), 505-518.

Diagnostic and Statistical Manual of Mental Disorders, Fifth Edition. Arlington, VA: American Psychiatric Association, 2013.

Endicott, J. (1984). Measurement of depression in patients with cancer. Cancer, 53, 22432248

Grassi, L., Johansen, C., Annunziata, M. A., Capovilla, E., Costantini, A., Gritti, P., ... \& Italian Society of Psycho-Oncology Distress Thermometer Study Group. (2013). Screening for distress in cancer patients: a multicenter, nationwide study in Italy. Cancer, 119(9), 1714-1721.

Hodges, L. J., Humphris, G. M., \& Macfarlane, G. (2005). A meta-analytic investigation of the relationship between the psychological distress of cancer patients and their carers. Social science \& medicine, 60(1), 1-12.

Khalil, A., Faheem, M., Fahim, A., Innocent, H., Mansoor, Z., Rizvi, S., \& Farrukh, H. (2016). Prevalence of depression and anxiety amongst cancer patients in a hospital setting: a cross-sectional study. Psychiatry journal, 2016.

Lederberg, M. S., \& Holland, J. C. (2011). Supportive psychotherapy in cancer care: An essential ingredient of all therapy. Handbook of psychotherapy in cancer care, 1 .

Linn, M. W., Linn, B. S., \& Harris, R. (1982). Effects of counseling for late stage cancer patients. Cancer, 49(5), 1048-1055.

Michopoulos, I., Douzenis, A., Kalkavoura, C., Christodoulou, C., Michalopoulou, P., Kalemi, G., ... \& Lykouras, L. (2008). Hospital Anxiety and Depression Scale (HADS): validation in a Greek general hospital sample. Annals of general psychiatry, 7(1), 4

Ming, V. M. W. (2002). Psychological predictors of marital adjustment in breast cancer patients. Psychology, health \& medicine, 7(1), 37-51.

Misch D. A. (2000). Basic strategies of dynamic supportive therapy. The Journal of psychotherapy practice and research, 9(4), 173-189.

Mukherjee, A., Mazumder, K., Kaushal, V., \& Ghoshal, S. (2017). Effect of Supportive Psychotherapy on Mental Health Status and Quality of Life of Female Cancer Patients Receiving Chemotherapy for Recurrent Disease. Indian journal of palliative care, 23(4), 399-402. https://doi.org/10.4103/IJPC.IJPC_73_17

National Cancer Institute (NIH) https://www.cancer.gov/

Nikbakhsh, N., Moudi, S., Abbasian, S., \& Khafri, S. (2014). Prevalence of depression and anxiety among cancer patients. Caspian journal of internal medicine, 5(3), 167.

Niedzwiedz, C. L., Knifton, L., Robb, K. A., Katikireddi, S. V., \& Smith, D. J. (2019). Depression and anxiety among people living with and beyond cancer: a growing clinical and research priority. BMC cancer, 19(1), 1-8.

Pardue, S. F., Fenton, M. V., \& Rounds, L. R. (1989). The social impact of cancer. Dimensions in oncology nursing: journal of the Division of Nursing, 3(1).

Pinsker H, Rosenthal R, McCullough L(1991): Dynamic supportive psychotherapy, in Handbook of Short-Term Dynamic Psychotherapy, edited by Crits-Christoph P, Barber JP. New York, Basic Books, pp 220-247

Pitman, A., Suleman, S., Hyde, N., \& Hodgkiss, A. (2018). Depression and anxiety in patients with cancer. Bmj, 361, k1415.

Razavi, D., Delvaux, N., Farvacques, C., \& Robaye, E. (1990). Screening for adjustment disorders and major depressive disorders in cancer in-patients. The British Journal of Psychiatry, 156(1), 79-83. 
Rosenthal, R. N., Muran, J. C., Pinsker, H., Hellerstein, D., \& Winston, A. (1999). Interpersonal change in brief supportive psychotherapy. The Journal of psychotherapy practice and research, 8(1), 55-63.

Sadoughi, M., Mehrzad, V., \& Mohammad Salehi, Z. (2017). The relationship of optimism and hope with depression and anxiety among women with breast cancer. IJNR, 12(2), $16-21$.

Shimizu, K., Nakaya, N., Saito-Nakaya, K., Akechi, T., Ogawa, A., Fujisawa, D., ... \& Tsugane, S. (2015). Personality traits and coping styles explain anxiety in lung cancer patients to a greater extent than other factors. Japanese journal of clinical oncology, 45(5), 456-463.

Spiegel, D., \& Yalom, I. D. (1978). A support group for dying patients. International Journal of Group Psychotherapy, 28(2), 233-245.

Stark, D. P., \& House, A. (2000). Anxiety in cancer patients. British journal of cancer, 83(10), 1261-1267. doi:10.1054/bjoc.2000.1405

Stedeford, A. (1979). Psychotherapy of the dying patient. The British Journal of Psychiatry, 135(1), 7-14.

Wen, S., Xiao, H., \& Yang, Y. (2019). The risk factors for depression in cancer patients undergoing chemotherapy: a systematic review. Supportive Care in Cancer, 27(1), $57-67$.

Winston, A., Rosenthal, R. N., \& Pinsker, H. (2004). Introduction to supportive psychotherapy. American Psychiatric Publishing, Inc.

Winters-Stone, K. M., Dobek, J., Bennett, J. A., Nail, L. M., Leo, M. C., \& Schwartz, A. (2012). The effect of resistance training on muscle strength and physical function in older, postmenopausal breast cancer survivors: a randomized controlled trial. Journal of Cancer Survivorship, 6(2), 189-199.

Wu, L., \& Wang, S. J. (2003). Psychotherapy improving depression and anxiety of patients treated with chemotherapy combined with radiotherapy. Chin J Clin Rehabil, 7(July (17)), 2462-2463.

Wu, Y. S., Lin, P. Y., Chien, C. Y., Fang, F. M., Chiu, N. M., Hung, C. F., ... \& Chong, M. Y. (2016). Anxiety and depression in patients with head and neck cancer: 6-month follow-up study. Neuropsychiatric disease and treatment, 12, 1029.

Yalom, I. D., \& Greaves, C. (1977). Group therapy with the terminally ill. The American journal of psychiatry.

Zigmond, A. S., \& Snaith, R. P. (1983). The hospital anxiety and depression scale. Acta psychiatrica scandinavica, 67(6), 361-370.

\section{Acknowledgement}

The author appreciates all those who participated in the study and helped to facilitate the research process.

\section{Conflict of Interest}

The author declared no conflict of interest.

How to cite this article: Karulkar P. (2020). Impact of supportive therapy in reducing anxiety and depression in middle aged cancer patients. International Journal of Indian Psychology, 8(4), 299-313. DIP:18.01.038/20200804, DOI:10.25215/0804.038 